\title{
Effects of Emotional Images on Cardiovascular Responses in Males with Coronary Artery Disease and in Healthy Males: The Role of Sensation Seeking
}

\author{
Davoud Ezzati ${ }^{1}$, Touraj Hashemi Nosrat Abad ' , Jalil Babapour \\ Kheiroddin ${ }^{1}$, Hassan Sabourimoghaddam ${ }^{1}$, Mohammadreza \\ Taban Sadeghi ${ }^{2}$, Hossein Namdar ${ }^{2,}{ }^{*}$, Babak Sadeghi ${ }^{1}$, \\ Masoumeh Hakimi ${ }^{3}$
}

${ }^{1}$ Department of Psychology, Faculty of Educational Sciences and Psychology, University of Tabriz, Iran

${ }^{2}$ Department of Cardiology, Cardiovascular Research Center, Tabriz University of Medical Sciences, Tabriz, Iran

${ }^{3}$ Department of Psychology, Faculty of Psychology, Azad University, Branch of Tabriz, Tabriz, Iran

* Corresponding author: Hossein Namdar, Department of Cardiology, Cardiovascular Research Center, Tabriz University of Medical Sciences, Tabriz, Iran. E-mail:

DOI: $10.21859 / \mathrm{ijcp}-03101$ namdar.hn@gmail.com

Submited: 09-15-2017

Accepted: 12-24-2017

Keywords:

Stressful Stimulus

Pleasant Stimulus

Coronary Artery Disease

Sensation

(C) 2018. International Journal of Cardiovascular Practice.

\begin{abstract}
Introduction: Individuals exposed to certain types of images, based on their personality features, experience different emotional states and physiological responses. The present study addressed the effects of stressful and pleasant stimuli on blood pressure and heart rate in male patients with coronary problems and healthy males based on sensation seeking levels.

Methods: One hundred and seventy eight male patients with coronary artery diseases referred to Madani Heart Hospital, Tabriz, Iran; and 185 healthy male subjects completed the Sensation Seeking Scale-form V (SSS-V). After obtaining acceptable scores, 100 patients and 100 healthy males were classified in four groups: high sensation seeker patients, low sensation seeker patients, high sensation seeker healthy subjects, and low sensation seeker healthy subjects (each group with 50 samples aged 30-49). First, blood pressures and heart rates were recorded before stimulus induction. Then, the participants were exposed to stressor pictures. After 15 minutes of relaxation, and a cognitive task, the participants were exposed to pleasant pictures. The blood pressure and heart rate were recorded after presenting the two stimuli.

Results: High sensation seeker patients achieved lower scores in diastolic blood pressure in comparison with low sensation seeker patients after presenting the stressful stimulus, and healthy high sensation seekers achieved lower scores in systolic blood pressure in comparison with healthy low sensation seekers presented with pleasant stimulus.

Conclusions: Low sensation seeker patients experienced negative emotions more than high sensation seeker patients. Therefore, the role of induced mood states may be important in relation to physical health.
\end{abstract}

\section{INTRODUCTION}

Coronary Artery Disease (CAD) is a group of diseases including stable angina pectoris, unstable angina pectoris, myocardial infarction, and sudden cardiac death [1]. It is within the group of cardiovascular diseases, from which this is the most frequent [2]. There are several known risk factors associated with $\mathrm{CAD}$, such as family history of premature $\mathrm{CAD}$, hypertension, physical inactivity and diabetes mellitus. Based on estimates, up to $50 \%$ of new CADs cannot be explained on the basis of standard risk factors, which shows a wide range of $\mathrm{CAD}$ risk factors [3]. CAD affected 110 million people and resulted in 8.9 million deaths in 2015 , which is $15.9 \%$ of all deaths; it is the most common cause of death global [4, $5]$. The risk of death from $\mathrm{CAD}$ for a given age has reduced between 1980 and 2010, particularly in developed countries 
[6]. Between 1990 and 2010, the number of patients with $\mathrm{CAD}$ during a given age also decreased [7]. In 2010 in the United States, almost $20 \%$ of those over 65 had CAD, while it was present in $7 \%$ of those 45 to 64 , and $1.3 \%$ of those 18 to 45 years old [8]. In personality psychology, people can be classified into certain types based on the configuration of their personal characteristics [9]. Studies have suggested that different personality types are associated with cardiovascular outcomes [10]. These studies found that different personality aspects can influence cardiovascular responses, since experience and emotion regulation are associated with cardiovascular function and personality dimensions are closely related to emotions [11]. There are several negative emotions such as depression, anxiety and anger which are associated with increased mortality [12-14]. Sensation seeking is a mood and personality variable with a biological basis that reflects individual differences in arousal levels. Sensation seeking is based on the ability to excite. Sensation seekers prefer regular brain stimulation, get tired of doing the same thing and are always looking to increase their motivation through stimulating experiences. Low sensation seekers prefer less brain stimulation and tolerate routine work relatively well [15]. Stress is one of the most common etiological factors in certain diseases such as $\mathrm{CAD}$ which is the leading cause of death associated with an inappropriate response to stress [16]. Individuals have different levels of vulnerability to stress which varies from time to time and among different individuals. This variation is caused by physiological and psychosocial differences between people [17]. The role that positive emotions play in coping with stress has prompted researchers to investigate this topic. It is possible that positive emotions occur in stressful situations alongside negative emotions [18]. The aim of the present study was to investigate the relationship of sensation seeking levels with cardiovascular responses to emotional images.

\section{METHODS}

This study was approved by the scientific committee of Psychology Department at the University of Tabriz. The study population included male patients with $\mathrm{CAD}$ who visited Madani Heart Hospital of Tabriz, Iran; a control group of healthy males aged $30-49$ years was also selected. CAD was defined as a history of myocardial infarction, or at least 50\% stenosis of one or more major epicardial coronary arteries by invasive coronary angiography. The study samples consisted of 178 male patients with $\mathrm{CAD}$ and a control group of 185 healthy males. First of all, the Zuckerman Sensation Seeking Scale Form V (SSS-V) was performed on subjects. All the participants were informed of study objectives and explanations were given about the questions and that they could withdraw at any time they wish. In cases where the subjects were not able to understand the concepts, the researcher clarified with more information. Patients with arrhythmias were excluded from the study. After completing the scale, 100 male patients ( 50 high sensation seekers and 50 low sensation seekers), as well as 100 healthy men (50 high sensation seekers and 50 low sensation seekers) were selected from the subjects who had earned higher scores than others matching in terms of demographic parameters. Before stimulus presentation, blood pressures and heart rates of the subjects were recorded and then the subjects were exposed to stressor images including 13 pictures of war crimes, which were presented by laptop in the form of slides, each for 14 seconds ( 3 minutes in total). At the end of the slideshow, the subjects' blood pressures and heart rates were measured by a digital arm sphygmomanometer. During a rest period of 15 minutes, the subjects completed a cognitive task (subtracting in 7's from 100) to neutralize the previous stimulus. Then, the subjects were exposed to pleasant images including 13 pictures of children under one year of age. Each slide was presented for 14 seconds ( 3 minutes in total) and then the subjects' blood pressures and heart rates were rechecked. All the pictures were selected from Google Images and approved by three psychology professors. Upon completion of the experiment, the results from the sphygmomanometer (blood pressure and heart rate) were recorded. In the present research, data were analyzed using descriptive statistics as well as independent samples t-test and Multivariate Analysis of Covariance (MANCOVA). Before analyzing the data, Kolmogorov-Smirnov test was used to test the normality distribution of the variables. BOX test was used to verify equality of covariance parameters assumption. In addition, Levene's test was used to examine assumption of equality of groups' co-variances $(\mathrm{P}>0.05)$. P value of $<0.05$ was considered significant.

\begin{tabular}{|lccccccc|}
\hline \multicolumn{2}{|l}{ Table1: Mean and Standard deviation of SBP, DBP, and HR } \\
\multicolumn{3}{|c}{$\begin{array}{c}\text { High level sen- } \\
\text { sation seekers }\end{array}$} & & & & \multicolumn{3}{c|}{$\begin{array}{c}\text { Low level sensa- } \\
\text { tion seekers }\end{array}$} \\
Dependent variable & $\begin{array}{c}\text { Before } \\
\text { stimulus }\end{array}$ & $\begin{array}{c}\text { After stressful } \\
\text { stimuli }\end{array}$ & $\begin{array}{c}\text { After pleasant } \\
\text { stimuli }\end{array}$ & $\begin{array}{c}\text { Before } \\
\text { stimulus }\end{array}$ & $\begin{array}{c}\text { After stressful } \\
\text { stimuli }\end{array}$ & $\begin{array}{c}\text { After pleasant } \\
\text { stimuli }\end{array}$ \\
Patients SBP & $132.14 \pm 3.35$ & $134.76 \pm 2.60$ & $127.20 \pm 5.12$ & $143.14 \pm 2.65$ & $140.96 \pm 14.03$ & $137.08 \pm 2.55$ \\
DBP & $98 \pm 2.71$ & $93.20 \pm 3.58$ & $90.96 \pm 2.67$ & $95.22 \pm 3.42$ & $96.80 \pm 2.24$ & $93.20 \pm 3.10$ \\
HR Healthy subjects & $79.28 \pm 3.28$ & $81.40 \pm 2.72$ & $78.88 \pm 3.63$ & $78.64 \pm 2.40$ & $81.40 \pm 2.20$ & $81.80 \pm 4.87$ \\
SBP & $112.06 \pm 4.36$ & $118.78 \pm 4.22$ & $107.56 \pm 4.28$ & $127.12 \pm 4.47$ & $126.40 \pm 3.16$ & $128.62 \pm 2.97$ \\
DBP & $76.70 \pm 2.45$ & $75.60 \pm 3.69$ & $75.16 \pm 3.31$ & $77.64 \pm 4.43$ & $81.28 \pm 3.09$ & $78.90 \pm 3.46$ \\
HR & $78 \pm 3.75$ & $78.60 \pm 2.35$ & $77.84 \pm 4.27$ & $79.34 \pm 3.97$ & $79.14 \pm 3.25$ & $77.92 \pm 2.60$ \\
\hline
\end{tabular}

Values are presented as mean \pm SD.

SBP: Systolic Blood Pressure; DBP: Diastolic Blood Pressure; HR: Heart Rate

High Level Sensation Seeking Patients $(\mathrm{N}=50)$; Low Level Sensation Seeking Patients $(\mathrm{N}=50)$; High level Sensation Seeking Healthy Subjects $(\mathrm{N}=50)$; Low Level Sensation Seeking Healthy Subjects $(\mathrm{N}=50)$ 


\begin{tabular}{|c|c|c|c|c|c|c|}
\hline \multirow[b]{2}{*}{$\begin{array}{l}\text { Changes in dependent } \\
\text { variable }\end{array}$} & \multicolumn{3}{|c|}{$\begin{array}{c}\text { Patients High sensation seekers versus Low } \\
\text { sensation seekers }\end{array}$} & \multicolumn{3}{|c|}{$\begin{array}{l}\text { Healthy subjects High sensation seekers versus } \\
\text { Low sensation seekers }\end{array}$} \\
\hline & Mean difference & Std. Error & P-Value & Mean difference & Std. Error & P-Value \\
\hline After stressful stimuli SBP & -5.463 & 4.451 & 0.221 & -5.031 & 7.621 & 0.510 \\
\hline DBP & -10.228 & 1.330 & 0.001 & -1.249 & 2.277 & 0.584 \\
\hline HR After pleasant stimuli & -0.359 & 1.358 & 0.792 & -3.460 & 2.326 & 0.139 \\
\hline SBP & -1.235 & 2.189 & 0.573 & -19.728 & 3.748 & 0.001 \\
\hline DBP & -2.609 & 1.630 & 0.111 & -2.613 & 2.792 & 0.350 \\
\hline HR & -1.808 & 2.114 & 0.393 & 5.083 & 3.620 & 0.162 \\
\hline
\end{tabular}

SBP: Systolic Blood Pressure; DBP: Diastolic Blood Pressure; HR: Heart Rate

\section{RESULTS}

Table 1 shows the descriptive statistics of the participating groups. Both in pretest and posttest, the patients' levels of systolic and diastolic blood pressure were higher than the control group $(\mathrm{P}<0.001)$. In addition, levels of systolic blood pressure of the low sensation seekers were higher than the high sensation seekers. The regression slope also showed that there was no significant interaction between the groups and pretest scores in either systolic and diastolic blood pressure or heart rate. In other words, the regression slopes were homogeneous and the assumptions of the regression slopes were met.

Table 2 shows the comparison of mean differences between the variations of four groups before and after stimulations, in which the diastolic blood pressure of the high sensation seeker patients reduced significantly more in comparison with the low sensation seekers $(\mathrm{P}<0.001)$. Furthermore, the systolic blood pressure of the healthy high sensation seeker group reduced significantly more after the presentation of the pleasant stimulus $(\mathrm{P}<0.001)$, but there was no significant difference in the other cases.

\section{DISCUSSION}

The results of this study indicated that high sensation seeker patients showed a greater reduction in diastolic blood pressure compared with low sensation seeker patients following response to stressor images. In addition, the results showed that the healthy high sensation seeker group showed more reduction in systolic blood pressure compared with the healthy low sensation seekers when presented with a pleasant images. Eysenck, in his biological theory about personality, used excitation and inhibition terms which were first introduced by Pavlov. In his theory, Eysenck discusses about introversion-extraversion and neuroticism dimensions. According to Eysenck, the introverts' nervous system is naturally prone to stimulation and the nervous system of extroverts is naturally inclined to inhibition [19]. Gurrera (1990) and Furnham (1984) showed that there was a significant positive relationship between sensation seeking and extraversion $[20$, 21]. Eysenck (1986) also believed that sensation seeking was one of the features which described extraversion [22]. Zuckerman (1994) found that the sensation seeking dimension, like the extraversion dimension, was based on the ability to become aroused. To understand how the extraversion and high sensation seeking continuums are related to arousal, we should keep in mind that innate genetic differences can cause people to differ from each other in their Ascending Reticular Activating Systems (ARAS). The ARAS of the brain structure is responsible for brain arousal in response to an external stimulus. Introverted and low sensation seekers are characterized by ARAS sensitivity to low levels of stimulation and intolerance of high ARAS stimulation that acts to reduce external stimulus by low sensation seekers [23]. As a result, low sensation seekers exhibit phobic reactions toward perilous excitation sources such as snakes, altitudes and darkness [24]. Eysenck demonstrated that extraverts with a lack of ARAS sensitivity act with high sensation seeking in order to increase external stimuli and to reach optimal levels of arousal with a relatively high level of stimulation, and hence seek out intense stimulation [23]. For example, they prefer stimulation which causes abrupt bias responses and those which cause a loss of 5 to 10 seconds of heart rate and muscle tension, such as the physiological impact to the autonomic nervous system when exposed to a new stimuli that is complex or important from a personal point of view [25]. The interest of high sensation seekers towards those stimuli which cause biased reactions, help us to understand why they seek and prefer activities such as motorcycle riding, parachute jumping and speed [22]. Zuckerman in his surveys also proposed the hypothesis of hormonal impact on human sensation seekers [26]. The study on hormonal activities such as cortisol showed that this hormone is negatively correlated with high sensation seeking. In other words, the amount of these hormones in individuals with high sensation seeking is lower and the decrease in cortisol levels is a good explanation for determining why high sensation seekers suffer less from stress [23]. There is an evidence that extroverted people in a positive mood state had a greater reduction in systolic blood pressure than in a negative mood [27]. However, inconsistent with the current findings, Zuckerman and Russo (1992) showed that the blood pressures of extroverted and high sensation seekers were higher when compared with those who do not share these personal characteristics [28]. Extroverted people are sensitive to both positive and negative emotional stimuli $[29,30]$.

The results also showed that regardless of personal charac- 
teristics, the blood pressure of patients with CAD are higher than in healthy individuals. In explaining these results, it can be said that stress through physiological changes can lead to heart disease. It seems that stress has direct effects on the coronary arteries and heart muscle. In response to stress or exposure to a dangerous or threatening situation, heart rate increases, blood pressure rises and many changes occur in other body systems, e.g. blood vessels narrow, muscles contract and the blood flow to the brain and muscles increases. As a result of these changes, and the increased heart rate, cardiac oxygen demand rises and this can result in a heart attack or angina pectoris in people who have heart diseases. In addition, stress increases blood clot formation, which can cause partial or complete obstruction of a coronary artery and lead to heart attack. On the other hand, when the body's sympathetic hormone levels (e.g. adrenaline) are increased in response to stress, along with increased blood flow, these can cause damage to the arteries endothelium causing stiffness of the artery wall and produce plaque buildup or progration. All of these factors point to why people with heart disease often experience chest pain in stressful situations and also why heart attacks usually occur under these circumstances [31]. This study showed that in patients with CAD, there was a relationship between high scores of sensation seeking and reduction of diastolic blood pressure, and in healthy subjects there was a relationship between high scores of sensation seeking and reduction of systolic blood pressure. Therefore, the role of induced mood states may be important in relation to physical health.

\section{AUTHORS' CONTRIBUTION}

Data collection: Ezzati, Sadeghi, Hakimi; Data analysis and interpretation: Hashemi, Babapour; Drafting the article: Ezzati, Namdar; Critical revision of the article: Sabouri Moghaddam, Taban Sadeghi; Final approval of the version to be published: Ezzati, Namdar.

\section{CONFLICTS OF INTERESTS}

There is no conflict of interest.

\section{FUNDING}

The authors declared that there is no funding or support.

\section{REFERENCES}

1. Wong ND. Epidemiological studies of CHD and the evolution of preventive cardiology. Nat Rev Cardiol. 2014;11(5):276-89. DOI: 10.1038/nrcardio.2014.26 PMID: 24663092

2. Mortality GBD, Causes of Death C. Global, regional, and national age-sex specific all-cause and cause-specific mortality for 240 causes of death, 1990-2013: a systematic analysis for the Global Burden of Disease Study 2013. Lancet. 2015;385(9963):117-71. DOI: 10.1016/S0140-6736(14)61682-2 PMID: 25530442

3. Disease GBD, Injury I, Prevalence C. Global, regional, and national incidence, prevalence, and years lived with disability for 310 diseases and injuries, 1990-2015: a systematic analysis for the Global Burden of Disease Study 2015. Lancet. 2016;388(10053):1545602. DOI: 10.1016/S0140-6736(16)31678-6 PMID: 27733282

4. Mortality GBD, Causes of Death C. Global, regional, and national life expectancy, all-cause mortality, and cause-specific mortality for 249 causes of death, 1980-2015: a systematic analysis for the Global Burden of Disease Study 2015. Lancet. 2016;388(10053):1459-
544. DOI: 10.1016/S0140-6736(16)31012-1 PMID: 27733281

5. Moran AE, Forouzanfar MH, Roth GA, Mensah GA, Ezzati M, Murray CJ, et al. Temporal trends in ischemic heart disease mortality in 21 world regions, 1980 to 2010: the Global Burden of Disease 2010 study. Circulation. 2014;129(14):1483-92. DOI: $10.1161 /$ CIRCULATIONAHA.113.004042 PMID: 24573352

6. Moran AE, Forouzanfar MH, Roth GA, Mensah GA, Ezzati M, Flaxman A, et al. The global burden of ischemic heart disease in 1990 and 2010: the Global Burden of Disease 2010 study. Circulation. 2014;129(14):1493-501. DOI: 10.1161/CIRCULATIONAHA.113.004046 PMID: 24573351

7. Centers for Disease C, Prevention. Prevalence of coronary heart disease--United States, 2006-2010. MMWR Morb Mortal Wkly Rep. 2011;60(40):1377-81. PMID: 21993341

8. Marmot MG, Bosma H, Hemingway H, Brunner E, Stansfeld S. Contribution of job control and other risk factors to social variations in coronary heart disease incidence. Lancet. 1997;350(9073):235-9. PMID: 9242799

9. Knyazev GG, Slobodskaya HR. Personality types and behavioural activation and inhibition in adolescents. Pers Individ Differ. 2006;41(8):1385-95. DOI: 10.1016/j.paid.2005.11.035

10. Dannemann S, Matschke K, Einsle F, Smucker MR, Zimmermann $\mathrm{K}$, Joraschky $\mathrm{P}$, et al. Is type-D a stable construct? An examination of type-D personality in patients before and after cardiac surgery. J Psychosom Res. 2010;69(2):101-9. DOI: 10.1016/j.jpsychores.2010.02.008 PMID: 20624508

11. Jonassaint CR, Why YP, Bishop GD, Tong EM, Diong SM, Enkelmann HC, et al. The effects of neuroticism and extraversion on cardiovascular reactivity during a mental and an emotional stress task. Int J Psychophysiol. 2009;74(3):274-9. DOI: 10.1016/j.ijpsycho.2009.09.012 PMID: 19818369

12. Kawachi I, Sparrow D, Spiro A, 3rd, Vokonas P, Weiss ST. A prospective study of anger and coronary heart disease. The Normative Aging Study. Circulation. 1996;94(9):2090-5. PMID: 8901656 13. Kubzansky LD, Kawachi I, Spiro A, 3rd, Weiss ST, Vokonas PS, Sparrow D. Is worrying bad for your heart? A prospective study of worry and coronary heart disease in the Normative Aging Study. Circulation. 1997;95(4):818-24. PMID: 9054737

14. Matthews KA, Glass DC, Rosenman RH, Bortner RW. Competitive drive, pattern $\mathrm{A}$, and coronary heart disease: a further analysis of some data from the Western Collaborative Group Study. J Chronic Dis. 1977;30(8):489-98. PMID: 893653

15. Zuckerman M. The psychophysiology of sensation seeking. J Pers. 1990;58(1):313-45. PMID: 2198341

16. Endler NS, Parker JD. Multidimensional assessment of coping: a critical evaluation. J Pers Soc Psychol. 1990;58(5):844-54. PMID: $\underline{2348372}$

17. Ezzati D. Effects of stressful and pleasant stimuli on blood pressure and heart rate in patients with cardiovascular disease compared with healthy subjects based on emotion seeking levels. M.A Thesis, Tabriz: University of Tabriz; 2012.

18. Taban Sadeghi M, Namdar H, Vahedi S, Aslanabadi N, Ezzati D, Sadeghi B. Effects of emotional stimuli on cardiovascular responses in patients with essential hypertension based on brain/behavioral systems. J Cardiovasc Thorac Res. 2013;5(4):167-71. DOI: 10.5681/jcvtr.2013.036 PMID: 24404349

19. Gomez R, Cooper A, Gomez A. Susceptibility to positive and negative mood states: test of Eysenck's, Gray's and Newman's theories. Pers Individ Differ. 2000;29(2):351-65. DOI: 10.1016/s01918869(99)00198-1

20. Gurrera RJ. Some biological and behavioral features associated with clinical personality types. J Nerv Ment Dis. 1990;178(9):55666. PMID: 2203879

21. Furnham A. Extraversion, sensation seeking, stimulus screening and Type 'A' behaviour pattern: The relationship between various measures of arousal. Pers Individ Differ. 1984;5(2):133-40. DOI: 10.1016/0191-8869(84)90045-x

22. Jeshvaghani AA, Manshaei G, Dehkordi KM, Vasefpour H. The Comparison of Sensation Seeking among Musicians, Visual, and Dramatic Artists. Procedia - Soc Behav Sci. 2012;46:3320-3. DOI: $\underline{10.1016 / j . s b s p r o .2012 .06 .059}$

23. Sabouri Moghaddam H, Babapour Kheyroddin J, Ezzati D, Aslan Abadi N, Foroughi Asl R, Sadeghi B, et al. Effects of stressful stimulus on blood pressure and heart rate in patients with cardiovascular disease in comparison with healthy subjects based on emotion 
seeking levels. J Mod Psychol Res. 2015;10(38):149-65.

24. Anderson G, Brown RI. Real and laboratory gambling, sensation-seeking and arousal. Br J Psychol. 1984;75 ( Pt 3):401-10. PMID: 6487928

25. Neary RS, Zuckerman M. Sensation seeking, trait, and state anxiety, and the electrodermal orienting response. Psychophysiology. 1976;13(3):205-11. PMID: 1273223

26. Resnick SM, Gottesman, II, McGue M. Sensation seeking in opposite-sex twins: an effect of prenatal hormones? Behav Genet. 1993;23(4):323-9. PMID: 8240211

27. Rafi'eenia P, Azad-Fallah P, Fathi-Ashtiani A, Rasulzade KT: Effect of mood states on cardiovascular responses based on extraversion and neuroticism personality dimensions. Journal of Behavioral Sciences. 2009;3(2):85-91

28. Russo KR, Zuckerman M. Psychological, physiological and phys- ical characteristics of subjects at risk for essential hypertension. Pers Individ Differ. 1992;13(1):61-8. DOI: 10.1016/0191 $\underline{8869(92) 90219-f}$

29. Bartussek D, Becker G, Diedrich O, Naumann E, Maier S. Extraversion, neuroticism, and event-related brain potentials in response to emotional stimuli. Pers Individ Differ. 1996;20(3):301-12. DOI $\underline{10.1016 / 0191-8869(95) 00175-1}$

30. Gong P, Xi S, Li S, Cao G, Zhang P, Shen G, et al. Effect of Val66Met polymorphism in BDNF on attentional bias in an extroverted Chinese Han population. Acta Neurobiol Exp (Wars). 2013;73(2):280-8. PMID: 23823988

31. Khoosfi H, Monirpoor N, Birashk B, Peighambari M. A comparative study of personality factors, stressful life events, and social support in coronary heart patients and non-patients. Contemp Psychol. 2007;2(3):41-8. 